\title{
Evaluation of Sleep Quality and Daytime Sleepiness in Dentistry Students
}

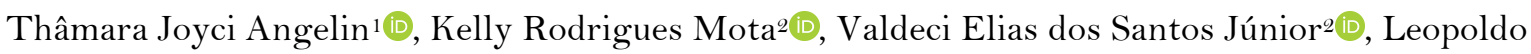 \\ Cosme Silva ${ }^{2}$, Mônica Vilela Heimer ${ }^{10}$
}

${ }^{1}$ Faculty of Dentistry, University of Pernambuco, Recife, PE, Brazil.

${ }^{2}$ Faculty of Dentistry, Federal University of Alagoas, Maceió, AL, Brazil.

Author to whom correspondence should be addressed: Mônica Vilela Heimer, Av. General Newton Cavalcanti, 1650, Tabatinga, Camaragibe, PE, Brazil. 54.756-220. Phone: +55 8131847661. E-mail: monica.vilelaheimer@gmail.com.

Academic Editor: Alidianne Fábia Cabral Cavalcanti

Received: 04 February 2020 / Accepted: 20 May 2020 / Published: 30 June 2020

How to cite this article: Angelin TJ, Mota KR, Santos Júnior VE, Silva LC, Heimer MV. Evaluation of sleep quality and
daytime sleepiness in dentistry students. Pesqui Bras Odontopediatria Clín Integr. 2020; $20: e 0003$.
https://doi.org/10.1590/pboci.2020.122

\begin{abstract}
Objective: To evaluate sleep quality and excessive daytime sleepiness in undergraduate dentistry students. Material and Methods: This research is characterized as an observational study of transversal type, having analysed undergraduate students in dentistry from a public university in the State of Pernambuco, Brazil. The sample consisted of 325 students enrolled between the 1st and 10th academic semester. Sleep quality was evaluated using the Pittsburgh Sleep Quality Index (PSQI), while excessive daytime sleepiness was analysed through the Epworth Sleepiness Scale (ESS). The t-Student and Mann-Whitney tests were used for the numerical values, with the F-test (ANOVA) or the Kruskal-Wallis test being used to compare more than two categories. Results: It was observed that $71.1 \%$ of students presented a poor sleep quality, with more than half of the students exhibiting excessive daytime sleepiness (58.1\%). A relationship between sleep quality and the academic semester was verified. However, gender and age were not associated with sleep quality or with excessive daytime sleepiness. Conclusion: A high prevalence of poor sleep quality and excessive daytime sleepiness was observed among undergraduate students in dentistry. The data suggest that the undergraduate degree in Dentistry can influence the students' quality of sleep, regardless of age or gender.
\end{abstract}

Keywords: Dyssomnias; Sleep Disorders, Intrinsic; Sleepiness; Students, Dental. 


\section{Introduction}

Sleep is an essential human condition characterised by a state of inactivity, muscle relaxation and a reduction in conscience in response to external cues and lower heart rates [1]. It plays a role in restoring, protecting and conserving energy, with the lack of sleep possibly leading to great damage in the individual's performance in the short and long-term, especially regarding the physical, occupational, cognitive and social functions of the body [2].

As it is a basic human need, sleep is one of the most relevant emerging subjects in modern society, as there is stark evidence that sleep deprivation and its consequent disorders can affect metabolic and inflammatory processes, having wide negative impacts on health [3], such as higher prevalence of diabetes, hypertension, coronary diseases and depression [4].

There is a remarkable relationship between sleep quality and excessive daytime sleepiness, with the latter defined as the greater probability of falling asleep in situations in which the individual should be awake [5], naturally leading to greater inattention, causing higher risks of car accidents, deficit of attention and learning [6].

Based on this premise, recent studies [7-9] have verified a clear relationship between sleep disorders and lower undergraduate academic performance. This is a result of an increasingly intense academic routine in universities, besides the pressure of obtaining a good future academic performance [10]. Therefore, it is evident that undergraduate students belong to a group with higher probability of presenting sleep deprivation and/or sleep fragmentation, which may compromise their physical and mental health [11].

Thus, as a result of the strong impact on the quality of sleep and level of health of the population, it is essential to monitor the risk profiles and outline more adequate prevention strategies, to better control the effects originated from sleep disorders. With this in mind and considering the importance of this issue, as well as the increasing relevance of the subject for public health, the present article evaluated the quality of sleep and excessive daytime sleepiness in undergraduate students in Dentistry from a Public University Institution in Brazil.

\section{Material and Methods}

Study Design and Sample

The present study is characterised as observational, of transversal type, having analysed undergraduate students in Dentistry from the University of Pernambuco (UPE). A survey was carried out with students from this University, with a population of 325 academics and a total of 430 students who were regularly enrolled between the 1st and 10th academic semesters.

\section{Data Collection}

The data was collected by a previously trained researcher, with the application of two surveys: the Pittsburgh Sleep Quality Index (PSQI) and the Epworth Sleepiness Scale (ESS).

The PSQI is a subjective measurement tool that analyses the quality of sleep within one month. The Brazilian version of the PSQI was applied [12]. The survey consists of 19 self-applied questions, divided into seven groups: subjective sleep quality, sleep disorders, use of sleeping pills and daytime dysfunction. Each component of the PSQI is awarded a score ranging between 0 and 3 points, with the sum of these values constituting a global score, varying from o to 21 points. When the total score ranges between 0 and 4 , the sleep quality is considered good; when varying between 5 to 10 , poor; and $>10$ being associated to the presence 
of sleep disorder [12]. In the present study, the quality of sleep was also characterised as good $(\leq 4)$ and poor $(\geq 5)$ (poor sleep quality + sleep disorder).

Excessive daytime sleepiness was evaluated using the Epworth Sleepiness Scale (ESS) [5]. This scale was designed based on a simple questionnaire, of easy application and interpretation, aimed at providing a general measurement of daytime sleepiness [13]. This questionnaire is also self-applicable, analysing the possibility of falling asleep under 8 ordinary situations [13]. According to the scenarios proposed, the patient chooses between 0 and 3, characterising the probability of falling asleep. The global score ranges from 0 to 24 , with up to 10 points considered normal, while scores higher than 10 can be associated to excessive daytime sleepiness and scores greater than 16 points being considered characteristic of excessive daytime sleepiness $[14]$.

The following sociodemographic characteristics were also analysed: gender, age, marital status, presence of children and academic semester enrolled. The students were divided into two age groups: 18-20 and 21-37 years old. Marital status was classified as either single or married. In turn, the academic semesters completed were divided into four different groups: from 1 st to 2 nd, 3 rd to 4 th, 5 th to 7 th and 8 th to 10 th.

\section{Data Analysis}

The categorical data were expressed as absolute and percentage frequencies. In turn, numerical data were expressed as mean values, standard deviation, median and percentiles 25 and 75 . The Chi-squared test was used to compare the correlation between two categorical variables. The t-Student and Mann-Whitney tests were used for the numerical values, with the F-test (ANOVA) or the Kruskal-Wallis test being used for the comparison of more than two categories. The statistical analysis was carried out using SPSS (Statistical Package for the Social Sciences) version 17, with a margin of $5 \%$ error.

\section{Ethical Considerations}

This study was approved by the Ethics Committee in Research from the University of Pernambuco (Process No. 1.432.302/2016), according to Resolution No. 466/2012 of the Brazilian National Ethics Committee in Research.

\section{Results}

Among the respondents, it was possible to identify a higher prevalence of female students (72.2\%), aged between 18 and 37 years old, being 98.2\% single, with only $2.5 \%$ having children (Table 1).

Table 1. Characteristics of the sample studied.

\begin{tabular}{|c|c|c|}
\hline Variables & $\mathbf{N}$ & $\%$ \\
\hline \multicolumn{3}{|l|}{ Gender } \\
\hline Male & 74 & 22.8 \\
\hline Female & 251 & 77.2 \\
\hline \multicolumn{3}{|l|}{ Academic Semester } \\
\hline 1 st to 2 nd & 66 & 20.3 \\
\hline $3 \underline{\text { rd }}$ to 4 th & 66 & 20.3 \\
\hline $5 \underline{\text { th }}$ to $7 \underline{\text { th }}$ & 90 & 27.7 \\
\hline $8 \underline{\text { th }}$ to $10 \underline{\text { th }}$ & 103 & 31.7 \\
\hline \multicolumn{3}{|l|}{ Age Group (Years Old) } \\
\hline 18 to 20 & 145 & 44.6 \\
\hline 21 to 37 & 180 & 55.4 \\
\hline
\end{tabular}




\begin{tabular}{|c|c|c|}
\hline \multicolumn{3}{|l|}{ Marital Status } \\
\hline Married & 6 & 1.8 \\
\hline Single & 319 & 98.2 \\
\hline \multicolumn{3}{|l|}{ Children } \\
\hline Yes & 8 & 2.5 \\
\hline No & 317 & 97.5 \\
\hline Total & 325 & 100.0 \\
\hline
\end{tabular}

Most students (71.1\%) had a poor quality of sleep and 21.5\% presented a certain type of sleep disorder. The percentage of students characterised as exhibiting sleep disorders was higher amongst students in the 8 th and 10th academic semesters (30.1\%). More than half of the sample presented daytime sleepiness, while $48.8 \%$ had excessive daytime sleepiness and 9.5\% severe sleepiness (Table 2 ).

Table 2. Evaluation of the quality of sleep and daytime sleepiness according to the academic semester enrolled.

\begin{tabular}{|c|c|c|c|c|c|c|c|c|c|}
\hline \multirow{4}{*}{$\begin{array}{l}\text { Academic } \\
\text { Semester }\end{array}$} & \multirow{4}{*}{$\mathbf{N}$} & \multicolumn{4}{|c|}{ Quality of Sleep } & \multicolumn{4}{|c|}{ Daytime Sleepiness } \\
\hline & & Good & Poor & With & p-value ${ }^{(1)}$ & Severe & Excessive & Normal & p-value $e^{(1)}$ \\
\hline & & & & Disorder & & & & & \\
\hline & & N (\%) & N (\%) & $\mathrm{N}(\%)$ & & N (\%) & N (\%) & N (\%) & \\
\hline 1 st to 2 nd & 66 & $2(3.0)$ & $59(89.4)$ & $5(7.6)$ & & $7(10.6)$ & $36(54.5)$ & $23(34.8)$ & \\
\hline $3 \mathrm{rd}$ to 4 th & 66 & $6(9.1)$ & $43(65.2)$ & $17(25.8)$ & & $3(4.5)$ & $30(45.5)$ & $33(50.0)$ & \\
\hline 5 th to 7 th & 90 & $10(11.1)$ & $63(70.0)$ & $17(18.9)$ & & $9(10.0)$ & $43(52.2)$ & $34(37.8)$ & \\
\hline 8 th to 10 th & 103 & $6(5.8)$ & $66(64.1)$ & $31(30.1)$ & & $12(11.7)$ & $45(43.7)$ & $46(44.7)$ & \\
\hline Total & 325 & $24(7.4)$ & $231(71.1)$ & $70(21.5)$ & $0.005^{*}$ & $31(9.5)$ & $158(48.6)$ & $136(41.8)$ & 0.422 \\
\hline
\end{tabular}

(1)According Pearson's chi-squared test; *Significant correlation at $5 \%$.

Table 3 shows the evaluation of the quality of sleep and sleepiness of students investigated, according to academic semester, age group and gender. A significant statistical association was observed between the quality of sleep and the semester enrolled $(\mathrm{p}<0.004)$. However, no statistically significant correlation was found between sleep quality and gender $(\mathrm{p}=0.963)$ or age group $(\mathrm{p}=0.430)$. In addition, no statistically significant association was found between sleepiness and the semester enrolled $(\mathrm{p}=0.235)$, gender $(\mathrm{p}=0.831)$ or age group $(\mathrm{p}=0.084)$.

Table 3. Evaluation of the quality of sleep and sleepiness, according to the academic semester enrolled, age group and gender.

\begin{tabular}{|c|c|c|c|c|}
\hline \multirow[b]{2}{*}{ Variables } & \multicolumn{2}{|c|}{ Quality of Sleep } & \multicolumn{2}{|c|}{ Daytime Sleepiness } \\
\hline & Mean (SD) & Median (P25; P75) & Mean (SD) & Median (P25; P75) \\
\hline \multicolumn{5}{|c|}{ Academic Semester } \\
\hline 1 st to 2 nd & $7.47 \pm 2.16$ & $7.00(6.00 ; 9.00)$ & $11.68 \pm 3.85$ & $12.00(9.00 ; 14.00)$ \\
\hline $3 r d$ to 4 th & $9.02 \pm 3.19$ & $9.00(7.00 ; 11.00)$ & $10.33 \pm 3.89$ & $10.50(8.00 ; 13.00)$ \\
\hline 5 th to 7 th & $7.78 \pm 2.89$ & $7.50(5.00 ; 10.00)$ & $11.39 \pm 3.94$ & $12.00(8.00 ; 14.25)$ \\
\hline 8 th to 10 th & $8.85 \pm 3.24$ & $8.00(6.00 ; 11.00)$ & $11.17 \pm 4.15$ & $11.00(8.00 ; 14.00)$ \\
\hline p-value & $0.004^{(1) *}$ & & $0.235^{(2)}$ & \\
\hline \multicolumn{5}{|l|}{ Age Group } \\
\hline 18 to 20 & $8.12 \pm 2.74$ & $8.00(6.00 ; 10.00)$ & $11.11 \pm 3.99$ & $11.00(8.00 ; 14.00)$ \\
\hline 21 to 37 & $8.46 \pm 3.19$ & $8.00(6.00 ; 10.00)$ & $11.21 \pm 3.99$ & $11.00(8.00 ; 14.00)$ \\
\hline p-value & $0.963^{(3)}$ & & $0.831^{(4)}$ & \\
\hline \multicolumn{5}{|l|}{ Gender } \\
\hline Male & $8.18 \pm 3.11$ & $8.00(6.00 ; 10.00)$ & $10.46 \pm 3.72$ & $11.00(8.00 ; 12.25)$ \\
\hline Female & $8.35 \pm 2.97$ & $8.00(6.00 ; 10.00)$ & $11.37 \pm 4.05$ & $12.00(9.00 ; 14.00)$ \\
\hline p-value & $0.430^{(3)}$ & & $0.084^{(4)}$ & \\
\hline
\end{tabular}

(ANOVA); ${ }^{\left({ }^{3}\right)}$ According to the Manm-Whitney test; ${ }^{(4)}$ According to the t-Student test with equal variance. 


\section{Discussion}

Although being preferable, the comparison of data with external populations is not always possible or even reliable. This is a result of regional, social and economic variations between the different samples. The data available in the literature show a great difference between academic degrees, academic syllabuses and socio-environmental realities.

Poor quality of sleep (QS) has been strongly considered an indication of a poor lifestyle, having stood out as a topic of great interest for public healthcare [15]. Sleep disorders have an intimate relationship with modern severe health conditions, such as depression, cardiovascular complications and diabetes [2]. Nevertheless, although sleep problems can have a negative influence on the appearance of these pathologies, these pathologies can, in turn, have a negative effect on the QS, which leads to a cyclical and vicious problem $[16]$.

The present research demonstrated that most undergraduate students in Dentistry presented a poor quality of sleep, with $21.5 \%$ having a sleep disorder. These findings corroborate with results observed by previous authors, who found a $95.3 \%$ prevalence of poor quality of sleep [17], and 60.25\% poor quality of sleep and $31.7 \%$ with the presence of sleep disorders [18]. On the other hand, this data is in disagreement with those previously reported among Brazilian undergraduate students in physiotherapy, having verified that most of them $(52 \%)$ presented a normal quality of sleep. However, as abovementioned, this analogy must be considered cautiously [19].

The present research included an analysis of students enrolled in ten academic semesters, with a high prevalence of poor quality of sleep observed in all academic semesters, though a greater percentage was observed in students from the 1 st and 2 nd academic semesters (89.4\%). This result is possibly due to the change in lifestyle of these recently enrolled undergraduate students, as they are not used to the university routine, as well as due to high academic demand and pressure felt in the first academic terms of university, which may lead to irregular sleeping patterns [20].

Regarding sleepiness, more than half of the students analysed in the present research exhibited Excessive Daytime Sleepiness (EDS). These findings are similar to those verified by other authors [10], who studied medical undergraduate students and residents, with this condition being present in $51.5 \%$ of the sample. Another researchers also observed a high prevalence of EDS in psychology undergraduates (54.5\%) $[21]$.

The present research found no relationship between the gender of the participants with QS and EDS. This result was also observed in medical students [22]. Moreover, no significant association between age was established and both dependent variables, i.e., QS and EDS. This result corroborates with the results of the study carried in the city of Campo Grande, State of Mato Grosso do Sul, Brazil [22]. Therefore, it can be implied that several stress factors are common among all undergraduates and tend to lead to similar sleeping issues, regardless of being either younger or older, female or male.

The data suggest that the university degree in Dentistry influences the quality of sleep of undergraduates, regardless of gender or age. These findings are important as they suggest the need to better monitor these students in emotional and physiological terms to better plan interventions aimed at improving sleeping patterns and help university directors be self-critical about the academic routine imposed on their students.

The present study presented some limitations intrinsic to the cross-sectional design adopted, being impossible to establish cause-effect implications. Nevertheless, the present article is representative for the 
population studied, offering original and important evidence on the quality of sleep and sleepiness among undergraduate students in Dentistry. It is essential to consider that the evaluation of these domains is strongly impacted by several factors, namely economic and social conditions and psychological balance. Longitudinal studies are necessary to determine the long-term effect of poor quality of sleep and excessive daytime sleepiness in undergraduate students in general, to prevent or mitigate possible damages that such variables can cause in the life quality of people.

\section{Conclusion}

A high prevalence of poor sleep quality and excessive daytime sleepiness was found among undergraduate students in Dentistry. The data suggest that the academic semester in which the student is enrolled can influence on their quality of sleep, regardless of gender or age.

\section{Authors' Contributions}

\begin{tabular}{|c|c|c|}
\hline TJA & (iD) $0000-0003-0346-6036$ & $\begin{array}{l}\text { Investigation, Formal Analysis, Writing - Original Draft Preparation and Writing } \\
\text { - Review and Editing. }\end{array}$ \\
\hline KRM & (iD) $0000-0002-1656-608 \mathrm{X}$ & Writing - Original Draft Preparation and Writing - Review and Editing. \\
\hline VESJ & (iD) $0000-0001-9748-5830$ & $\begin{array}{l}\text { Formal Analysis, Writing - Original Draft Preparation and Writing - Review and } \\
\text { Editing. }\end{array}$ \\
\hline LCS & (iD) $0000-0002-5755-1933$ & Writing - Original Draft Preparation and Writing - Review and Editing. \\
\hline MVH & (iD) $0000-0003-3842-192 \mathrm{X}$ & $\begin{array}{l}\text { Conceptualization, Methodology, Investigation, Formal Analysis and Writing - } \\
\text { Review and Editing. }\end{array}$ \\
\hline
\end{tabular}

\section{Financial Support}

None.

\section{Conflict of Interest}

The authors declare no conflicts of interest.

\section{References}

[1] Vassalli A, Dijk D. Sleep function: current questions and new approaches. Eur J Neurosci 2009; 29(9):1830-41. https://doi.org/10.1111/j.1460-9568.2009.06767.x

[2] Müller MR, Guimarães SS. Sleep disorders impact on daily functioning and life quality. Estud Psicol 2007; 24(4):51928. https://doi.org/10.1590/So103-166X2007000400011

[3] Colten HR, Altevogt BM (Editors). Sleep Disorders and Sleep Deprivation: An Unmet Public Health Problem. Washington: National Academies Press; 2006.

[4] Hublin C, Partinen M, Koskenvuo M, Kaprio J. Heritability and mortality risk of insomnia-related symptoms: a genetic epidemiologic study in a population-based twin cohort. Sleep 2011; 34(7):957-64. https://doi.org/10.5665/SLEEP.1136

[5] Bertolazi AN, Fagondes SC, Hoff LS, Pedro VD, Barreto SSM, Johns MW. Portuguese-language version of the Epworth sleepiness scale: validation for use in Brazil. J Bras Pneumol 2009; 35(9):877-83. https://doi.org/10.1590/S1806-37132009000900009

[6] Gottlieb DJ, Ellenbogen JM, Bianchi MT, Czeisler CA. Sleep deficiency and motor vehicle crash risk in the general population: a prospective cohort study. BMC Med 2018; 16(1):44. https://doi.org/10.1186/s12916-018-1025-7

[7] Adeosun SO, Asa SO, Babalola OO, Akanmu MA. Effects of night-reading on daytime sleepiness, sleep quality and academic performance of undergraduate pharmacy students in Nigeria. Sleep Biol Rhythms 2008; 6(2):91-4. https://doi.org/10.1111/j.1479-8425.2008.00338.x 
[8] Lemma S, Berhane Y, Worku A, Gelaye B, Williams MA. Good quality sleep is associated with better academic performance among university students in Ethiopia. Sleep Breath 2014; 18(2):257-63. https://doi.org/10.1186/s13104-015-1712-9

[9] Owens H, Christian B, Polivka B. Sleep behaviors in traditional-age college students: A state of the science review with implications for practice. J Am Assoc Nurse Pract 2017; 29(11):695-703. https://doi.org/10.1002/2327-6924.12520

[10] Cardoso HC, Bueno FCC, Mata JC, Alves APR, Jochims I, Vaz Filho IHR, et al. Assessing quality of sleep in medical students. Rev Bras Educ Méd 2009; 33(3):349-55. https://doi.org/10.1590/S0100-55022009000300005

[11] Araújo DF, Almondes KM. Sleep quality and its relationship with academic performance in college students of different shifts. Psico 2012; 43(3):350-9.

[12] Passos MHP, Silva HA, Pitangui ACR, Oliveira VMA, Lima AS, Araújo RC. Reliability and validity of the Brazilian version of the Pittsburgh Sleep Quality Index in adolescents. J Pediatr 2017; 93(2):200-6. https://doi.org/10.1016/j.jped.2016.06.006

[13] Johns MW. A new method for measuring daytime sleepiness: the Epworth sleepiness scale. Sleep 1991; 14(6):540-5. https://doi.org/10.1093/sleep/14.6.540

[14] Johns MW. Sensitivity and specificity of the multiple sleep latency test (MSLT), the maintenance of wakefulness test and the Epworth sleepiness scale: failure of the MSLT as a gold standard. J Sleep Res 2000; 9(1):5-11. https://doi.org/10.1046/j.1365-2869.2000.00177.x

[15] Santos-Silva R, Bittencourt LRA, Pires MLN, Mello MT, Taddei JA, Benedito-Silva AA, et al. Increasing trends of sleep complaints in the city of Sao Paulo, Brazil. Sleep Med 2010; 11(6):520-4. https://doi.org/10.1016/j.sleep.2009.12.011

[16] Rangel MA, Baptista C, Pitta MJ, Anjo S, Leite AL. Sleep quality and sleep disturbances in healthy children in Gaia: a cross sectional study. Rev Port Med Geral Fam 2015; 31(4):256-64.

[17] Araújo MFM, Lima ACS, Alencar AMPG, Araújo TM, Fragoaso LC, Damasceno MMC. Sleep quality assessment in college students from Fortaleza-CE. Texto Contexto Enferm 2013; 22(2):352-60. https://doi.org/10.1590/S0104-07072013000200011

[18] Lins AL, Magalhães ÁB. Qualidade do sono e sonolência diurna em estudantes de fisioterapia de uma instituição na Amazônia Brasileira. J Health Biol Sci 2017; 5(3):241-6. [In Portuguese].

[19] Almeida JOS, Siqueira PPS, Lima AMJ, Brasileiro-Santos MS, Galindo Filho VC. Daytime sleepiness and sleep quality in physical therapy students. ConScientiae Saúde 2011; 10(4):201-9. https://doi.org/10.5585/conssaude.v10i4.2981

[20] Pascotto AC, Santos BRM. Assessing sleep quality in health occupations students. J Health Sci Inst 2013; 31(3):30610.

[21] Danda GJN, Ferreira GR, Azenha M, Souza KFR, Bastos O. Sleep-wake cycle pattern and excessive daytime sleepiness in medical students. J Bras Psiquiatr 2005; 54(2):102-6.

[22] Souza JC, Magna LA, Reimão R. Excessive daytime sleepiness in Campo Grande general population, Brazil. Arq Neuropsiquiatr 2002; 60(3-A):558-62. 